\title{
Smoothed particle hydrodynamics (SPH) simulation of a tuned liquid damper (TLD) with angular motion
}

\section{Simulation d'un amortisseur liquide (TLD) en rotation à l'aide de la méthode SPH}

\author{
GABRIELE BULIAN, Department of Naval Architecture, Ocean and Environmental Engineering (DINMA), University of Trieste, \\ Via A. Valerio 10, 34127, Trieste, Italy. Tel.: +39-040-558-3444; e-mail: gbulian@ units.it (author for correspondence)
}

\begin{abstract}
ANTONIO SOUTO-IGLESIAS, Model Basin Research Group (CEHINAV), Naval Architecture Department (ETSIN), Technical University of Madrid (UPM), 28040 Madrid, Spain. Tel.: +34913367156; e-mail: antonio.souto@upm.es (author for correspondence)
\end{abstract}

LOUIS DELORME, Eurocopter, ETVDO, Aéroport de Marseille-Provence, 13725 Marignane Cedex, France.

Tel.: +33442851514; e-mail: louis.delorme@eurocopter.com

ELKIN BOTIA-VERA, Model Basin Research Group (CEHINAV), Naval Architecture Department (ETSIN), Technical University of Madrid (UPM), 28040 Madrid, Spain.Tel.: +34913367156; e-mail: elkinmauricio.botia@upm.es

\begin{abstract}
The roll motion response of a single degree of freedom (SDOF) structural system to which a rigid rectangular partially filled liquid tank has been attached is considered. The SDOF structural system with the empty tank is first described with a mathematical model and this model is validated by performing decay experiments as well as experiments in which periodic excitations are applied to the system. The responses are accurately predicted by the model. The accuracy of these predictions allows us to study both experimentally and numerically, with weakly compressible SPH, the performance of the partially filled tank as a tuned liquid damper (TLD). The sloshing flows inside the tank comprise the onset of breaking waves which make the TLDs devices extremely difficult to model, especially for the potential flow multimodal approaches commonly used to simulate these sorts of coupled systems. In order to characterise the wave breaking effects on the response curves, tests have been performed with liquids of different viscosity, the increasing viscosity preventing the onset of breaking waves. The capabilities of SPH to treat this coupling problem are assessed and the results show that SPH is able to capture a substantial part of the physics involved in the addressed phenomena but further work remains still to be done relating to a more accurate treatment of the laminar viscosity and turbulence effects.
\end{abstract}

\section{RÉSUMÉ}

La réponse en roulis d'un système à un degré de liberté (SDOF), auquel est fixée une cuve rectangulaire partiellement remplie de liquide, est étudiée dans cet article. Dans une première partie, un modèle mathématique est proposé pour le système SDOF, calibré à l'aide de résultats expérimentaux d'oscillations libres et forcées, avec une excitation périodique. La réponse du système est reproduite avec précision par le modèle. L'efficacité de la cuve en tant qu'amortisseur liquide (TLD) est ensuite analysée expérimentalement et numériquement en utilisant la méthode de simulation SPH. Pour résoudre ces problèmes de couplage, des méthodes basées sur la théorie du potentiel sont généralement utilisées. Dans le cas présent, leur utilisation est limitée à cause de la formation de vagues déferlantes lors du ballotement du liquide dans la cuve. Une plus grande viscosité du liquide réduisant la formation de ces vagues, des expériences ont été effectuées avec des liquides de différentes viscosités pour quantifier l'impact des déferlantes sur la réponse globale du système couplé. La capacité de la méthode SPH pour résoudre ce problème est discutée et les résultats montrent que les principaux phénomènes physiques sont reproduits avec SPH. Cependant, des travaux restent nécessaires quant au traitement de la viscosité laminaire et à la partie turbulente de l'écoulement.

Keywords: Roll, SDOF, single degree of freedom systems, smoothed particle hydrodynamics, SPH, TLD, tuned liquid damper, wave breaking

\section{Introduction}

The risk of occurrence of severe damage or structural failures in buildings during a catastrophic event like an earthquake or a hurricane can be reduced by adopting techniques to increase the damping characteristics of a structure. A tuned liquid damper
(TLD) system represents an efficient and simple technique to increase the damping of a structure. It involves the attachment of one or multiple partially filled liquid- tanks to the structures. The TLD systems rely on the sloshing waves that appear at the free surface of the fluid to produce a counter force and torque thus dampening the initial motion. The growing interest in TLDs 
is due to their low capital and maintenance cost and their ease of installation into existing and new structures. Very important examples of these devices are the Shin Yokohama Prince Hotel, the Hobart Tower in Tasmania (Kareem et al. 1999) or the $1300 \mathrm{t}$ one installed in the Comcast Center in Philadelphia, PA, claimed to be the largest in the world.

In the existing literature two theories can be found to describe the response of a TLD to external excitations. The first one consists of imposing a periodic motion on the TLD by using a shaking table or a forced roll motion device and measuring the response in terms of lateral force or moment (Reed et al. 1998, Tait et al. 2005, Souto-Iglesias et al. 2006). This measurement is not usually straightforward because the response of the tank liquid cannot be completely detuned from the structure itself when registered. Therefore some superposition hypotheses on the Fourier analysis of the empty tank and partially filled tank responses aimed at extracting the liquid response are needed. The period of the forced motion is related with the natural period of the structure and the TLD is designed to have a maximum response at this excitation period. The design parameters are the shape of the tank, the liquid depth and the use of baffles inside the tank.

The other approach, more complex, and the one the present paper deals with, is to consider the motion response of the coupled system tank-structure, subjected to external excitation in terms of force, moment or even induced motion to the tank interfaced with an elastic structure. With this second approach, not only the natural period of the structure is considered; the damping characteristics, inertia and restoring terms are also relevant in the dynamic analysis. Real motions of the structure are the outcome of this process and such motions can be compared with design limit states, for instance (Banerji et al. 2000, Frandsen 2005, Delorme et al. 2006, Attari and Rofooei 2008).

Modelling TLDs fluid responses has been conducted using a range of approaches mostly based on mechanical analogies (Tait and Deng 2008), potential flow models of the free surface fluid flow (Frandsen 2005, Attari and Rofooei 2008, Ikeda and Nakagawa 1997, Ikeda 2003) or most commonly, non-linear shallow water wave theory (Sun and Fujino 1994, Reed et al. 1998, Banerji et al. 2000, Tait et al. 2005). None of these has tried to properly model the effects of breaking waves on increasing the dampening effects of the TLD devices. Nevertheless, quoting Frandsen (2005),

It should be noted that, if the tank size is large enough, the effects of viscosity and surface tension can be neglected and the energy dissipation will be caused by wave breaking only.

Sun and Fujino (1993) proposed an analytical model for a TLD in which the breaking waves effects were considered by empirical corrections to the response. This model was later used by Banerji et al. (2000) who studied the particularities of strong earthquakes motions to find that a larger liquid-mass to structure-mass ratio is required for a TLD to remain effective as structural damping increases. In the field of civil engineering TLDs are mostly based on the force generated by partially filled tanks as a consequence of an imposed rectilinear (mostly horizontal with respect to the gravitational acceleration) motion.
TLDs are also used in the marine field, under the name of passive anti-roll tanks, to dampen the roll motion of, especially, fishing vessels (Bass 1998), whilst for large cargo ships active anti-rolling tanks are usually preferred. However, in contrast to the civil engineering case, the dampening effect on roll given by the TLD is obtained through the moment generated by the tank as a consequence of an imposed angular motion. In the field of Naval Architecture, the roll motion equation was coupled with experimentally determined fluid moments for an oscillating free surface tank (Van den Bosch and Vugts 1966) whilst Francescutto and Contento (1999) exploited the mechanical equivalence developed by Graham and Rodriguez (1952) to provide a 2-DOF analytical model which is nonlinear in respect to roll, and linear in respect to the DOF associated to the fluid sloshing. SDOF models for roll are often used to simulate the roll behaviour in beam seas (Bulian and Francescutto 2004) and an example of analytical nonlinear SDOF descriptions of roll motion coupled with direct CFD calculations for the free surface tank can be found in (Armenio et al. 1996). Rognebakke and Faltinsen (2003) analyzed the coupled problem in the sway case of a box excited by waves, in comparison to experimental data.

Numerical methods for solving the equations of Navier-Stokes offer another possibility of calculating the effects of the fluid on the ship motion. Armenio et al. (1996) used an improved Marker and Cells (MAC) methods to simulate the flow in stabilizer tanks, Van Daalen et al. (2001) applied Volume of Fluid (VOF) technique to a similar application.

Regarding experimental work on the coupling problem, a few studies have been reported using the shaking table for horizontal excitations (Sun and Fujino 1994), but not much in relation to angular motions; the work by Pirner and Urushadze (2007) considers to some extent damping effects under angular motion. In the marine engineering field, regarding roll motion, existing approaches have relied on a sinusoidal definition of waves' induced moments (Rognebakke and Faltinsen 2003, Armenio et al. 2006, 2006b).

In the present paper, a SDOF (single degree of freedom) structure with a partially filled tank is considered, with roll motion modelled by means of a 1-DOF approach. This means that the damper acts as an angular damper whilst most of the previously described works correspond to horizontal excitation. The moment created by the fluid with respect to the rolling axis is simulated and results for the roll angle are compared. The motion is excited by the moment created by a transversally (in a tank fixed reference system) moving mass with imposed motion. Experiments have been performed using fluids of different viscosity in order to assess the influence of breaking. A similar approach was taken by Pirner and Urushadze (2007), because water is not a suitable liquid to be used in footbridges which was the problem they were interested in.

The numerical simulations are performed using SPH. One of the most attractive features of SPH is its Lagrangian character allowing it to deal with very steep deformations of the free surface including breaking waves, as illustrated in the shallow water case studied in this article. SPH has been applied with success to sloshing problems with periodic oscillation in sway 
(Landrini et al. 2003) and roll (Souto et al. 2006) for shallow water cases. It had also been applied to a coupled motion problem (Delorme et al. 2006), showing promising results that had been compared with those obtained with a multimodal approach. Nevertheless, in Delorme et al. (2006), comparisons with experimental results were not possible because they were not available at that time. In the present paper, an experimental SDOF model has been analysed and modelled and it will serve as a benchmark data supplier for the comparisons with the SPH computations. The problem represents a significant challenge for any numerical method and specifically for SPH due to the extent in time of the real phenomena to be simulated as will be later discussed.

\section{Experiments: Test cases}

The experiments were conducted with the tank testing device of the CEHINAV group (Fig. 1). The standard forced motion configuration of the device, used regularly in the design of antiroll tanks, that had been previously used for instance in Souto et al. (2006), was modified by disconnecting the driving electrical engine from the tank holding structure, in order to allow the free motion of the tank.

The tank chosen for the simulations is depicted with its dimensions in Fig. 2. It is narrow along the $z$-direction, i.e. the direction perpendicular to the paper in comparison with the horizontal and vertical dimensions. This is intended to have predominantly a two dimensional flow, since the code used for the simulations will be a 2D one, faster than the 3D ones, and which can be more easily modified and validated than a $3 \mathrm{D}$ one, which usually requires arrangements for parallel computing.

The rotating shaft is placed $470 \mathrm{~mm}$ above the base line of the tank. Having the tank below the rotating shaft makes it possible in this case to have a still stable configuration. Having the base of the tank at a considerable distance from the rotation axis makes the flow more interesting in terms of generated waves' propagation.

There is a horizontal linear guide $600 \mathrm{~mm}$ long placed just at the rotation center, aimed at simplifying some terms in the motion equation (Fig. 3). This linear guide consists of a controllable electrical engine that laterally moves a weight with a specified motion. This weight will mimic the external excitation to the system (e.g. the wave action on the roll motion).

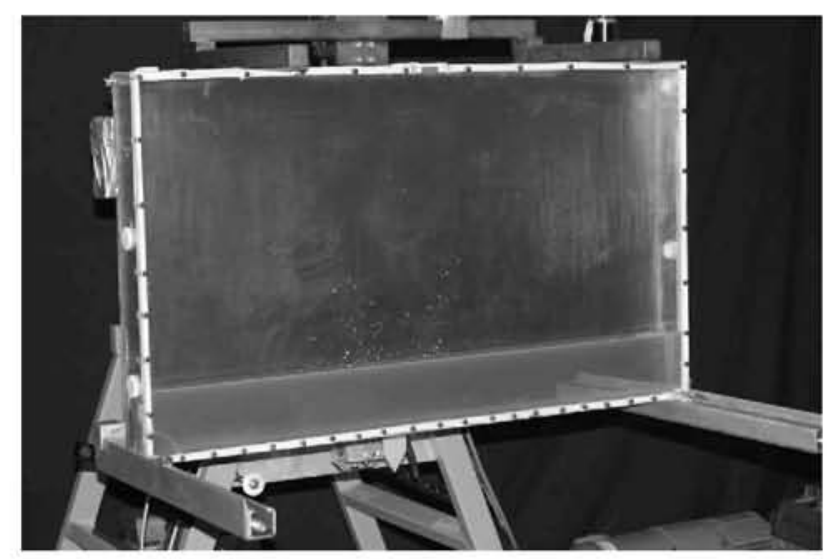

Figure 1 Tank testing device

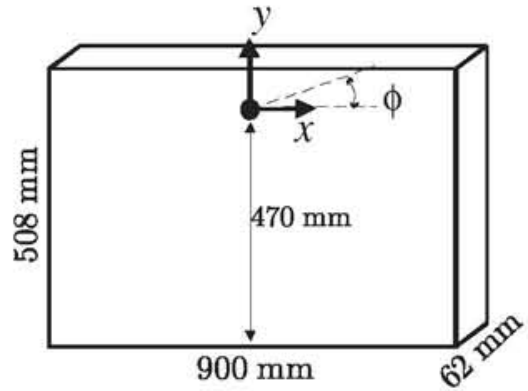

Figure 2 Tank dimensions

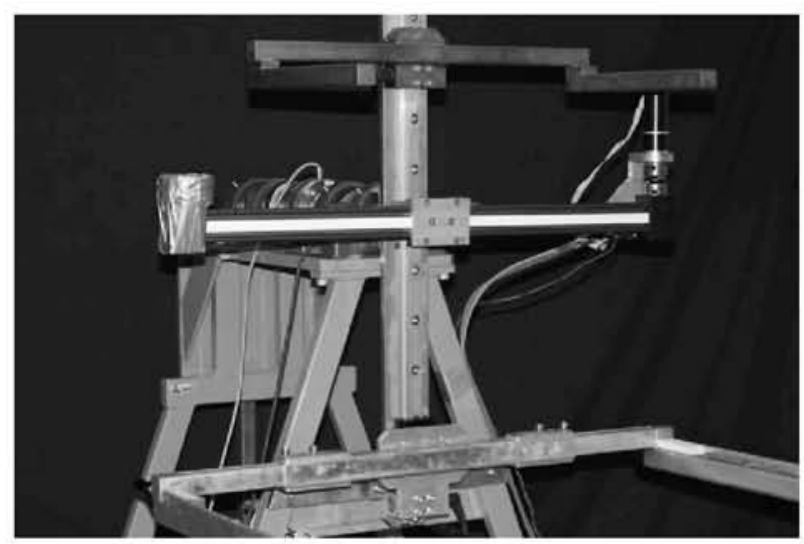

Figure 3 Sliding mass device

The natural frequency of the rigid system with the empty tank $\omega_{0}$, as will be later discussed, is $3.26 \mathrm{rad} / \mathrm{s}$. The water depth $(H)$ whose first sloshing frequency matches $\omega_{0}$ has been chosen for the experiments $(92 \mathrm{~mm})$. The test matrix is defined by choosing three moving weight frequencies $0.9 \omega_{0}, 1.0 \omega_{0}$ and $1.1 \omega_{0}$ and 4 moving weight motion amplitudes $A(50 \mathrm{~mm}, 100 \mathrm{~mm}, 150 \mathrm{~mm}$ and $200 \mathrm{~mm}$ ) for each of the three liquids (water, sunflower oil and glycerin). For all cases, the moving mass $m$ is the same $m=4.978 \mathrm{~kg}$. A summary of the test cases is reported in Table 1 .

It is important to define which are the Reynolds numbers of our experimental flows. The characteristic velocity will be related to the bore front propagation velocity of the equal height dambreak $(\sqrt{g H})$; the characteristic length will be taken as the water depth $H$. The physical constants of the three liquids and the corresponding Reynolds numbers are documented in Table 2.

According to the obtained Reynolds number, the water cases will be fully turbulent and the glycerin ones will be completely laminar. With oil there will be cases falling into either laminar, turbulent or transition regimes. We will focus on the water cases in the present paper, using the other liquids' cases as reference regarding the onset of splashing and breaking waves and the influence of these phenomena on the damping effect of the TLD.

Table 1 Test matrix (repeated for each liquid: water, sunflower oil and glycerin)

\begin{tabular}{lllll}
\hline$\omega / \omega_{0} \backslash A$ & $50 \mathrm{~mm}$ & $100 \mathrm{~mm}$ & $150 \mathrm{~mm}$ & $200 \mathrm{~mm}$ \\
\hline 0.9 & $0.9 / 50$ & $0.9 / 100$ & $0.9 / 150$ & $0.9 / 200$ \\
1.0 & $1.0 / 50$ & $1.0 / 100$ & $1.0 / 150$ & $1.0 / 200$ \\
1.1 & $1.1 / 50$ & $1.1 / 100$ & $1.1 / 150$ & $1.1 / 200$ \\
\hline
\end{tabular}


Table 2 Physical properties (units SI) of the liquids: $\rho$ for density, $\mu$ for the dynamic viscosity, $v$ for the kinematic viscosity. Re for the Reynolds number

\begin{tabular}{lllll}
\hline & $\rho$ & $\mu$ & $\nu$ & $\operatorname{Re}$ \\
\hline Water & 998 & $8.94 \mathrm{e}-4$ & $8.96 \mathrm{e}-7$ & 97546 \\
Oil & 900 & 0.045 & $5 \mathrm{e}-5$ & 1748 \\
Glycerine & 1261 & 0.934 & $7.4 \mathrm{e}-4$ & 118 \\
\hline
\end{tabular}

\section{Analytical model of the SDOF structural system}

\subsection{General}

An analytical model of the SDOF structural system used in the experiments is needed in order to have it incorporated into the structure part of the SPH code. It was obtained by rigorously analyzing the dynamics of the system and by obtaining the coefficients after carefully analyzing a set of tests with the empty tank and thereafter finding a data-consistent damping term model. The analytical model used to describe the behaviour of the system is, in general, as follows:

$$
\begin{aligned}
& {\left[I_{0}+m \xi_{m}^{2}(t)\right] \cdot \ddot{\phi}+2 m \xi_{m}(t) \dot{\xi}_{m}(t) \cdot \dot{\phi}-g \cdot S_{G} \cdot \sin (\phi)} \\
& +m \cdot g \cdot \xi_{m}(t) \cos (\phi)=Q_{\text {damp }}(t) \\
& Q_{\text {damp }}(t)=-K_{d f} \cdot \operatorname{sign}(\dot{\phi})-B_{\phi} \cdot \dot{\phi}
\end{aligned}
$$

where

- $\phi[\mathrm{rad}]$ is the roll angle

- $g\left[\mathrm{~m} / \mathrm{s}^{2}\right]$ is the gravitational acceleration

- $I_{0}\left[\mathrm{~kg} \cdot \mathrm{m}^{2}\right]$ is the polar moment of inertia of the rigid system with respect to the rotation axis

- $m[\mathrm{~kg}]$ is the mass of the moving weight

- $\xi_{m}(t)[\mathrm{m}]$ is the instantaneous (imposed) position of the excitation weight along the linear guide (tank-fixed reference system)

- $\dot{\xi}_{m}(t)[\mathrm{m} / \mathrm{s}]$ and $\ddot{\xi}_{m}(t)\left[\mathrm{m} / \mathrm{s}^{2}\right]$ are the first and second time derivatives of $\xi_{m}(t)[\mathrm{m}]$

- $S_{G}=M_{R} \cdot \eta_{G}[\mathrm{~kg} \cdot \mathrm{m}]$ is the static moment of the rigid system with respect to the rotation axis

- $M_{R}[\mathrm{~kg}]$ is the total mass of the rigid system

- $\eta_{G}[\mathrm{~m}]$ is the(signed) distance of the centre of gravity of the rigid system with respect to the rotation axis (tank-fixed reference system)

- $Q_{\text {damp }}(t)=-K_{d f} \cdot \operatorname{sign}(\dot{\phi})-B_{\phi} \cdot \dot{\phi}[\mathrm{N} \cdot \mathrm{m}]$ is the assumed form of roll damping moment comprising:

○ A dry friction term $-K_{d f} \cdot \operatorname{sign}(\dot{\phi})$ with $K_{d f}[\mathrm{~N} \cdot \mathrm{m}]$ being the dry friction coefficient

- A linear damping term $-B_{\phi} \cdot \dot{\phi}$ with $B_{\phi}[\mathrm{N} \cdot \mathrm{m} /(\mathrm{rad} / \mathrm{s})]$ being the linear damping coefficient

By using a set of inclining tests as well as decay tests, the unknown parameters can be determined, including the natural frequency of the rigid system $\omega_{0}$. The values of these parameters can be found in Table 3 .
Table 3 Mechanical parameters of the rigid system

\begin{tabular}{llc}
\hline Quantity & Units & Value \\
\hline$S_{G}$ & $\mathrm{~kg} \cdot \mathrm{m}$ & -29.2 \\
$I_{0}$ & $\mathrm{~kg} \cdot \mathrm{m}^{2}$ & 26.9 \\
$K_{d f}$ & $\mathrm{~N} \cdot \mathrm{m}$ & 0.540 \\
$B_{\phi}$ & $\mathrm{N} \cdot \mathrm{m} /(\mathrm{rad} / \mathrm{s})$ & 0.326 \\
$\omega_{0}$ & $\mathrm{rad} / \mathrm{s}$ & 3.26 \\
\hline
\end{tabular}

\subsection{Analytical model assessment}

\subsubsection{General}

Before moving to the simulation of the behaviour of the rigid system coupled with a fluid in the tank, it is worth checking the simulation capabilities of the model described in the previous section when the fluid is absent. The objective of this assesment is to test its accuracy for later introducing the fluid effect on the right hand side of equation (1) as an extra term for the moment. The parameters that will be used are those reported in Table 3 . In the case of decay tests, $m=0$, whereas in the case of forced rolling tests, the motion of the shifting mass $m$ is imposed during each experiment. Hence, $\xi_{m}(t), \dot{\xi}_{m}(t)$ and $\ddot{\xi}_{m}(t)$ are known functions of the time. To be more precise $\xi_{m}(t)$ is directly measured, whilst $\dot{\xi}_{m}(t)$ and $\ddot{\xi}_{m}(t)$ are obtained from numerical derivation after fitting a least square cubic spline to the moving weight motion signal in order to mitigate the noise influence in the derivatives (see Fig. 4 for an example of the sliding mass motion curves).

\subsubsection{Free decays without fuid: comparison between simulations and experiments}

Figure 5 shows a comparison between an experimental decay and a simulated decay using the parameters reported in Table 3 . The agreement is excellent in the range of roll angles above about 2-3 deg. For smaller oscillations the assumed damping model underestimates the actual damping of the system, hence the simulated time histories are slightly under-damped in the tail region. A better modelling of the friction damping or a modification of
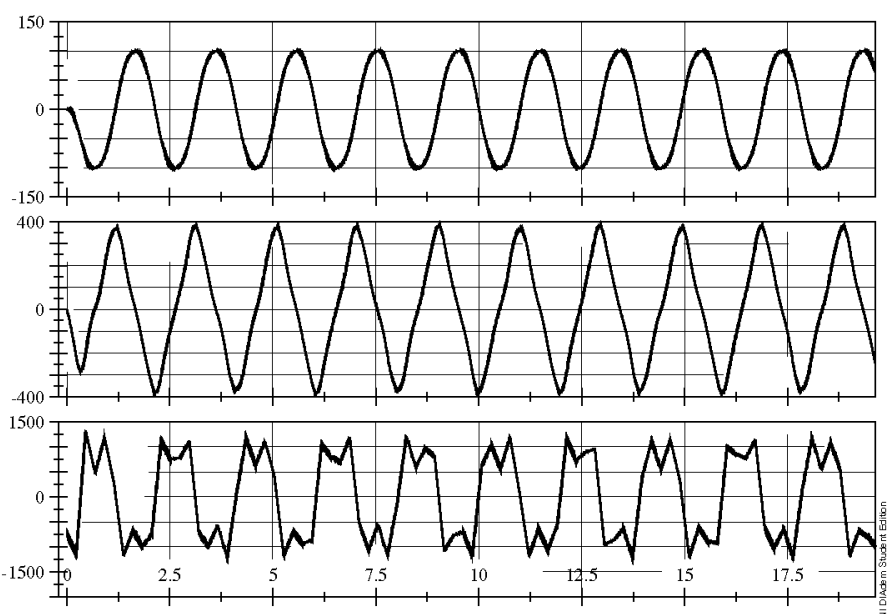

Figure 4 Empty tank, $A=100 \mathrm{~mm}, \omega=0.9 \omega_{0}, \xi_{m}(t)$ (top), $\dot{\xi}_{m}(t)$ (middle), $\ddot{\xi}_{m}(t)$ (bottom) 

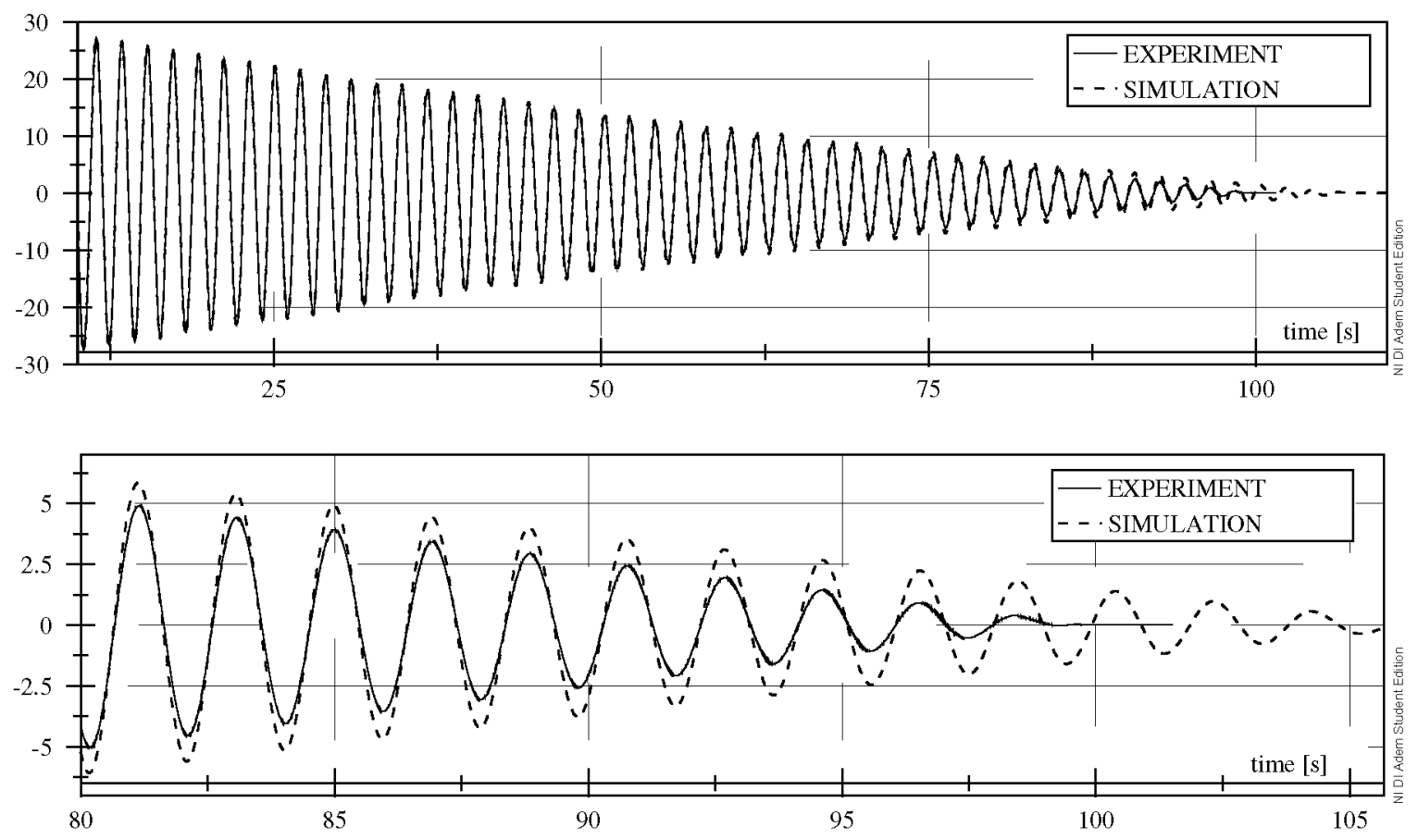

Figure 5 Comparison between experimental and simulated free decay angles (complete curve at the top and curve tail at the bottom)

the damping characteristics of the system would be therefore necessary in the case of interest in the region of small amplitude roll motions.

\subsubsection{Forced roll without fluid: comparison between simulations and experiments}

A series of tests with the empty tank and the moving mass have been performed in order to check the capability of the model 1-2 to reproduce the experimentally measured rolling motion of the system. The test matrix was described in Section 2. It is extremely important to note that due to technical limitations in the control of the instantaneous position $\xi_{m}(t)$, the motion $\xi_{m}(t)$ of the sliding mass is periodic with period $T_{\text {osc }}$ but not purely sinusoidal. Instead, each period of $\xi_{m}(t)$ is obtained by joining, approximately, four parabolic branches. The actual position $\xi_{m}(t)$ of the sliding mass is measured during each experiment.

Figures 6 and 7 show two examples covering some of the possibilities reflected in the test matrix. The match is good enough to ensure that the rigid system model is adequate to proceed with the liquid coupling simulations.

\section{Fluid model}

\subsection{Tank motion equation}

The formulation (1) is modified by an extra moment $Q_{\text {fluid }}(t)$ on the right hand side when there is fluid present in the tank:

$$
\begin{gathered}
{\left[I_{0}+m \xi_{m}^{2}(t)\right] \cdot \ddot{\phi}+2 m \xi_{m}(t) \dot{\xi}_{m}(t) \cdot \dot{\phi}-g \cdot S_{G} \cdot \sin (\phi)} \\
+m \cdot g \cdot \xi_{m}(t) \cdot \cos (\phi)=Q_{\text {damp }}(t)+Q_{\text {fluid }}(t)
\end{gathered}
$$

We will try to model this extra term using SPH comparing the results with those from experiments.
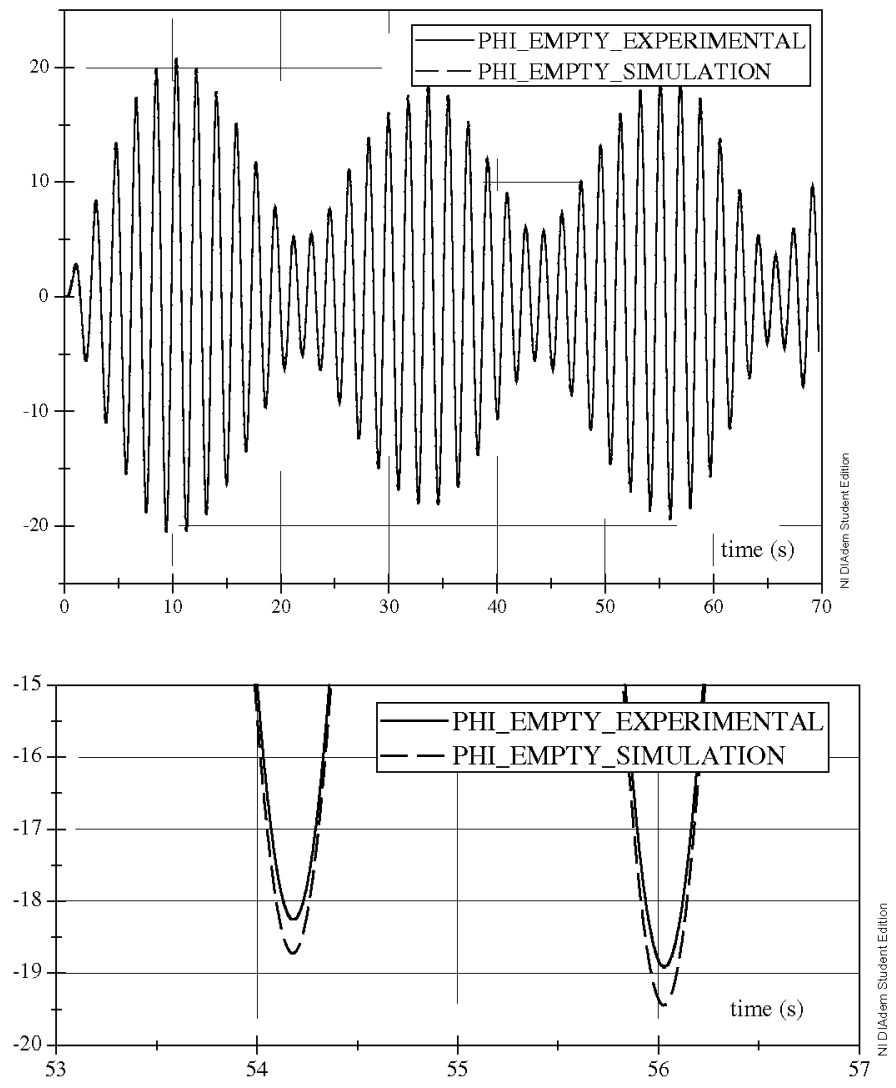

Figure 6 Roll angle of the empty tank, $A=200 \mathrm{~mm}, \omega=1.1 \omega_{0}$. Complete curve (top), curve detail (bottom)

\subsection{SPH model}

The SPH formulation used for this paper is the weakly compressible one (Monaghan 1994), in which the closure of the system formed by the compressible mass and momentum conservation equations is achieved by means of an equation of state (EOS) that 


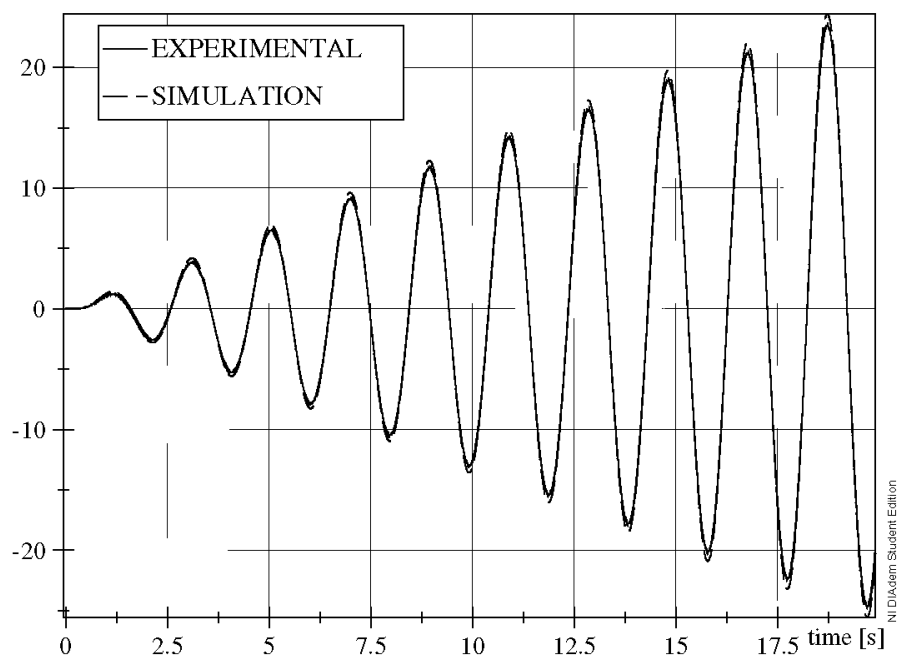

Figure 7 Roll angle of the empty tank, $A=100 \mathrm{~mm}, \omega=\omega_{0}$

correlates pressure with density. This EOS is defined in such a way that the density variations are very small, thus modelling a quasi-incompressible fluid.

There is a different possibility in which the pressure field is obtained by solving a Poisson equation at every time step (Koshizuka and Oka 1996, Cummins and Rudman 1999). The main problem with this approach for free surface flows is that the dynamic condition on the free surface (pressure equal zero) needs to be imposed explicitly. This requires a therefore explicit definition of the free surface geometry. This is a major drawback when simulating highly fragmented flows as those occurring in wave breaking events. On the other hand having a fully consistent approach to a liquid behaviour, which is, within a reasonable range, incompressible, has some advantages as well. Firstly there is an explicit geometric compatibility between the mass and the volume. Secondly and maybe most importantly, the incompressible approach allows a semi-implicit time integration of the system of equations. This is very good for improving the stability of the integration schemes which in turn allows the use of longer time steps. This advantage is prejudiced by the effort needed to solve the Poisson equation for the pressure at every time step.

There is an ongoing interesting debate among the SPH community at the moment as to which of the two previously described approaches is more convenient for simulating free surface flows (Shao 2005, Lee et al. 2008). It is the authors' opinion that the biggest advantage of SPH dealing with an extreme free boundary problem like the violent free surface flows occurring with a liquid subject to gravity forces and external strong normal and tangential reactions at the fixed boundaries, is the weakly compressible one. The main reason is that with the weakly compressible approach there is no need to define explicitly the free surface and therefore breaking, fragmentation and recomposition are inbuilt in the numerical approach to the physical problem. This is the main justification for using this approach in this paper.

Another important aspect of the computation is the use or not of MLS normalized kernels (Dilts 1999) for performing the interpolations as well as the periodic reinizialization of the density field with such interpolation in order to reset the compatibility between the volume, the mass and the density field (Colagrossi and Landrini 2003). Using normalized kernels becomes quite important when fluid fields are evaluated close to the boundaries and density reinizalization is important to remove some oscillations in the pressure field. In the present case there is no need to evaluate any specific field (pressure for instance) because we are interested only in the motion of the tank which acts as an integrator of all the fluid loads. Therefore, we think using those techniques would not contribute much in this particular case.

In the first SPH approaches to free surface incompressible flows (Monaghan 1994), the main aim was to solve inertia and gravity driven flows. An artificial viscosity term was included that prevented particles crossing their trajectories as well as provided some additional diffusion that increased the stability of the time integration. The approach was later seen to model accurately viscous laminar flows (Monaghan 2005) and works as a very dissipative (often too dissipative) term in high Reynolds number flows. A very promising approach, not yet implemented by the authors, relies on Riemann solvers to resolve the interaction between particles; this makes a big difference in the viscous interactions (Le Touzé et al. 2008).

\subsection{Boundary conditions}

The implementation of the boundary conditions has been achieved by using Ghost Particles (Colagrossi and Landrini 2003), which work well for a rectangular domain like the present one. For more details on the SPH formulation with application to the assessment of localised values like the wave impact pressures, see Delorme et al. (2008). It is important to note that the numerical Reynolds number is two orders of magnitude less than the physical one, when comparing with water. In Colagrossi et al. (2008) shallow depth sloshing with the three liquids here used and similar geometric constraints was studied. A detailed analysis was performed justifying the unfeasibility of reaching with the SPH simulation the physical Reynolds number in the water case. The Reynolds number used in the present computations will be in the same range as experiments with oil. It was also discussed that modeling the boundary layers was not possible for the oil and water cases. This analysis has served as basis for using free-slip conditions in the present paper.

\section{Results of the simulations}

\subsection{General}

The natural period of the system $T 0$ is approximately $1.927 \mathrm{~s}$. The liquid height has been chosen so that the first sloshing period obtained from the linear theory will also be $T 0$. There will be simulations regarding off-resonance conditions but the most interesting cases correspond to the resonance ones, and in particular those for which the differences between the three fluids in the dampening effects are worth noting, which correspond to the smallest moving mass amplitudes: $50 \mathrm{~mm}$ and $100 \mathrm{~mm}$. For $50 \mathrm{~mm}$ the roll angles are large enough to obtain results of reasonable accuracy. However, as discussed in section 3.2.2, for these 
Table 4 Amplitude reduction ratio (amplitude partially filled tank/amplitude empty tank)

\begin{tabular}{lrlll}
\hline$A$ & $50 \mathrm{~mm}$ & $100 \mathrm{~mm}$ & $150 \mathrm{~mm}$ & $200 \mathrm{~mm}$ \\
\hline Glycerin & 28.4 & 43.0 & 58.7 & 66.2 \\
Oil & 13.1 & 31.4 & 51.4 & 61.9 \\
Water & 6.4 & 23.6 & 46.7 & 59.3 \\
SPH & 10.4 & 32.2 & 45.5 & 58.5 \\
\hline
\end{tabular}

cases inaccuracies have been observed concerning the modelling of damping, and such inaccuracies could have influenced also the results from SPH simulations. Therefore, the $100 \mathrm{~mm}$ amplitude cases will be in principle the ones that merit more study. The resonance cases of higher amplitudes show in turn other important features, like for instance that some fluids are able to limit the structure motions whilst others, due to their viscosity, do not provide under the same conditions enough damping to put an upper limit the roll angle in resonance conditions. This will be later discussed.

\subsection{Resonance cases}

\subsubsection{General}

In the resonance tank tests, for some of the combinations between the liquids and the sliding mass motion amplitudes, the structural damping was not enough to stop the growth of the roll angle before reaching the device limit ( 45 degrees). One variable that will be discussed is the reduction ratio in amplitude between the partially filled tank and the empty tank roll angles (percentage) in a specific period of time. A ratio close to $100 \%$ will mean that the liquid has no dampening effect. A ratio close to $0 \%$, will mean that the resulting amplitude is very small. The ratio will be established taking the maximum values of the partially filled tank roll angle and the empty tank roll angle. The values of this ratio are reported in Table 4 , with a row corresponding to the SPH simulations.

The differences in this ratio for the three liquids are most substantial for the small amplitude cases, as expected. We will describe first the $100 \mathrm{~mm}$ amplitude case, which is the most significant, and we will go later through the other three cases.

\subsubsection{Amplitude $=100 \mathrm{~mm}$}

In this case, the reduction ratio ranges from 23.6 for water to 43.0 for glycerin (Table 4, analysis performed from 0 to $35 \mathrm{~s}$, end time in the empty tank experiment). The time evolution of the roll angle can be appreciated in Fig. 8 and in more detail in Fig. 9. In Fig. 8 it can be also appreciated that the tank roll angle is bounded for the three liquids (oil falls between water and glycerin case).

There is a substantial difference between water and glycerin and the dynamics are quite different as well, as can be seen in Fig. 10 (bottom and top) where the time is referred to the first sloshing period $T 0$. The glycerin gets stuck on the methacrylate wall after the wave passage which makes the visualization of its motion more difficult. On the other hand, there is not such a big difference between the global dynamics of the oil and water cases, but the differences in the dampening characteristics are substantial (Fig. 9). As can be appreciated in Fig. 10, in the water case there is the formation of a bore that will develop into a plunging breaking wave, whereas in the oil case, a mild spilling wave is formed with presumably significantly less dissipation (see also Fig. 12). A specific dye was used for the sunflower oil instead of the fluorescine used for water and glycerin and that cannot be dissolved in oil. This is the reason for the different shade of the oil picture in Figs. 10 and 12.

The SPH results show that the water amplitude reduction ratio error is around $9 \%$ in this case. The simulations were run with 800,3200 , and 6400 particles and the convergence in terms of the roll angle curve was satisfactory. The best results in terms of roll angle correspond to oil. This is expected because SPH simulation Reynolds number is of the order of the oil experiments, as discussed in section 4.3 .

When analysing individual frames, the dynamics as simulated by SPH is more similar to that of water, as can be seen in Fig. 11 for instance, which can be easily assimilated to the water case amongst the three of Fig. 10.

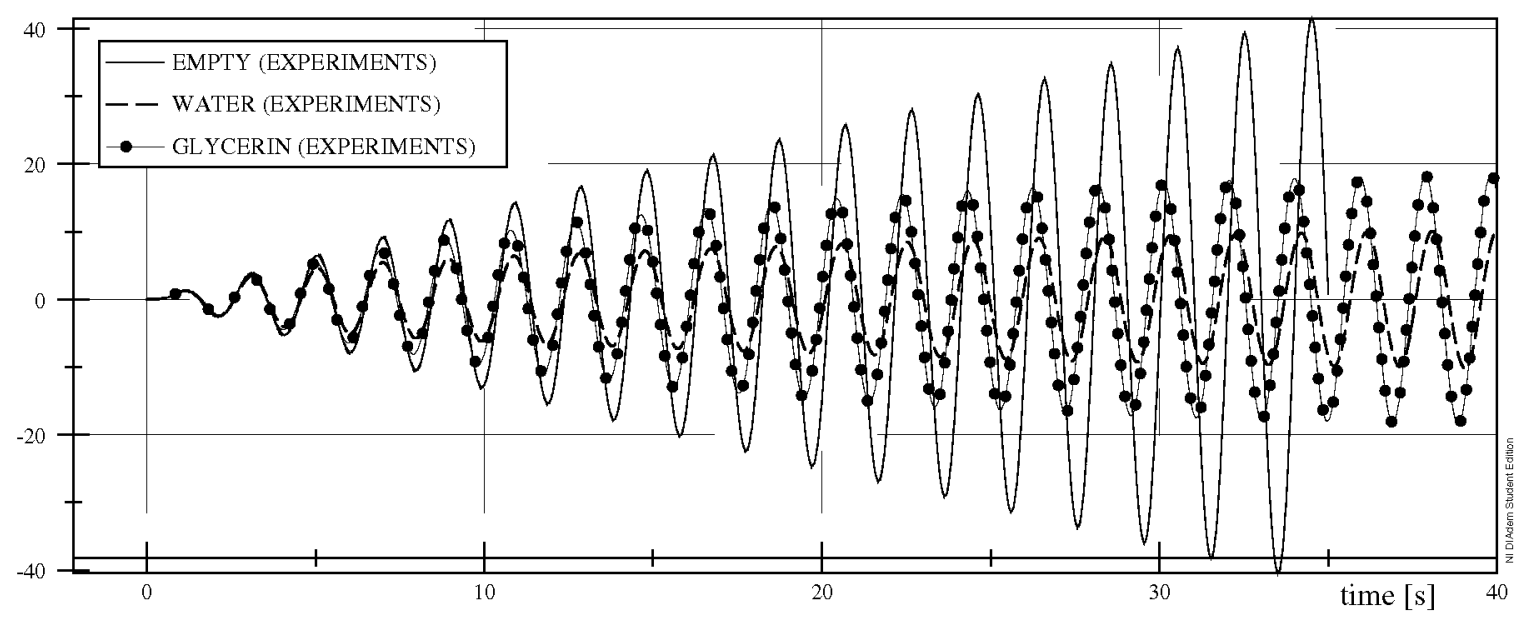

Figure 8 Roll angle, $A=100 \mathrm{~mm}, \omega=\omega_{0}$ 


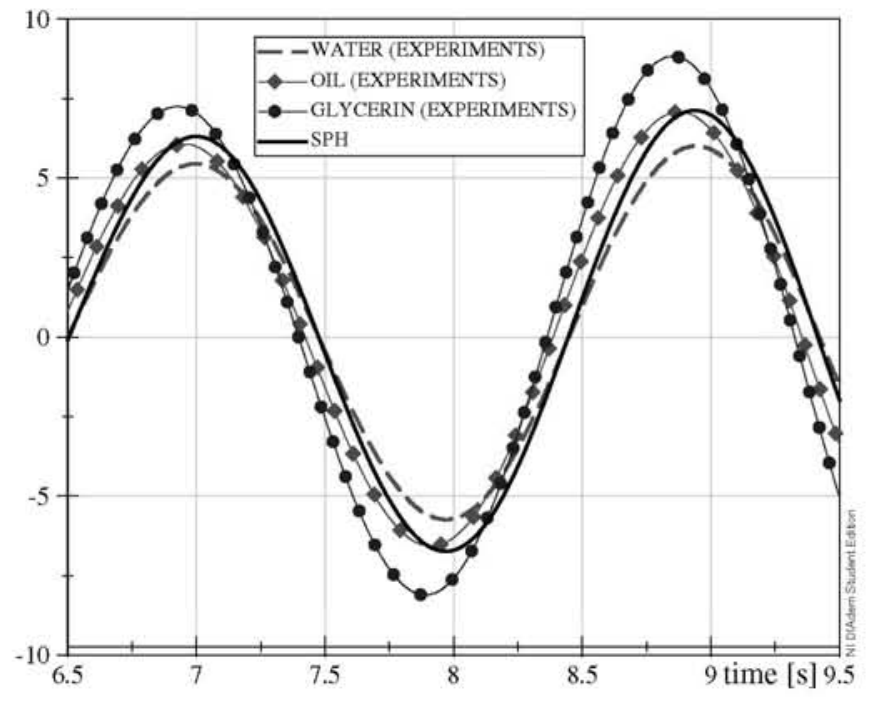

Figure 9 Roll angle (zoom), $A=100 \mathrm{~mm}, \omega=\omega_{0}$

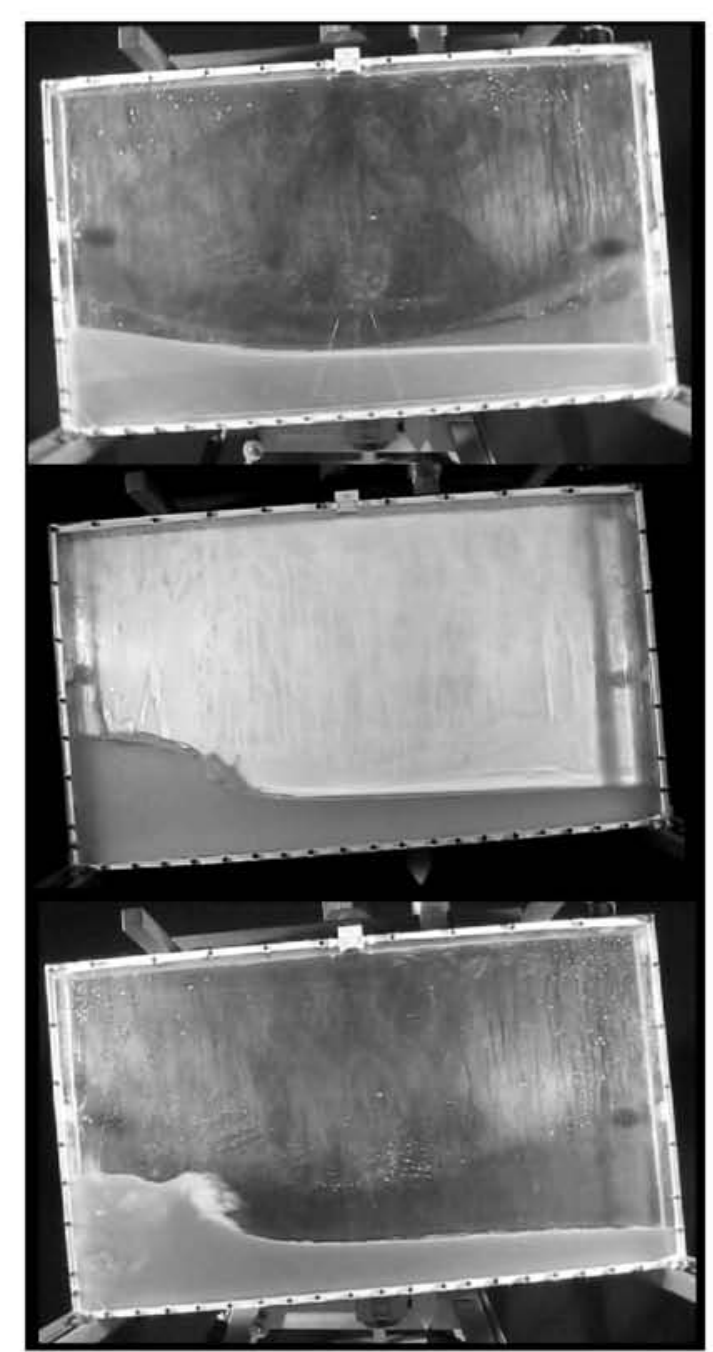

Figure $10 A=100 \mathrm{~mm}, \omega=\omega_{0}, t / T 0=8.66$. Glycerin (top), oil (middle), water (bottom). The orange color arrow signals the moving mass position

The velocity fields are plotted in Figs. 11 and 13. It can be seen that the gradients in the breaking area are significant. This is an indication of the violence of the impact of the jet with the free surface, in which a substantial amount of energy is dissipated.

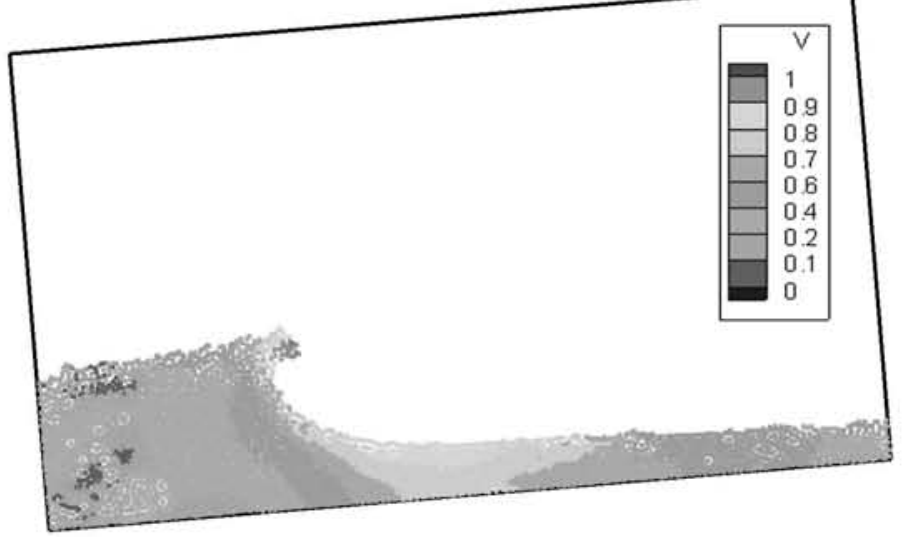

Figure 11 SPH velocity field, $t / T 0=8.66$ (see fig. 10 for details)

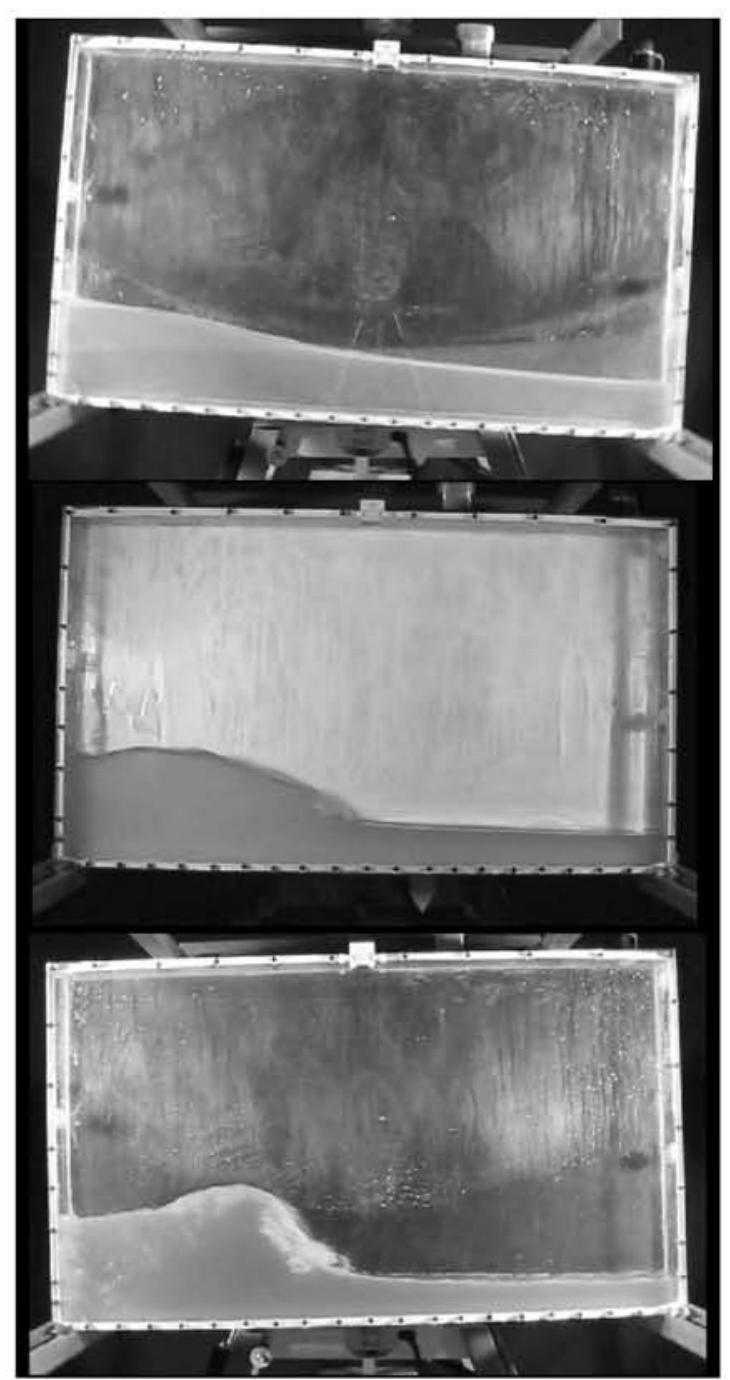

Figure $12 t / T 0=8.85$ (see Fig. 10)

\subsubsection{Amplitude $=50 \mathrm{~mm}$}

The SPH results show that the water amplitude reduction ratio error is around 5\% in this case (see Table 4). In Fig. 14 it can be also appreciated that the tank motion is limited by the three liquids (oil falls in between water and glycerin curves). For small roll angles, larger errors are visible that, however, could be partially due to the problems in the damping model of rigid system at small rolling amplitudes, as explained in section 3.2.2. The difference 


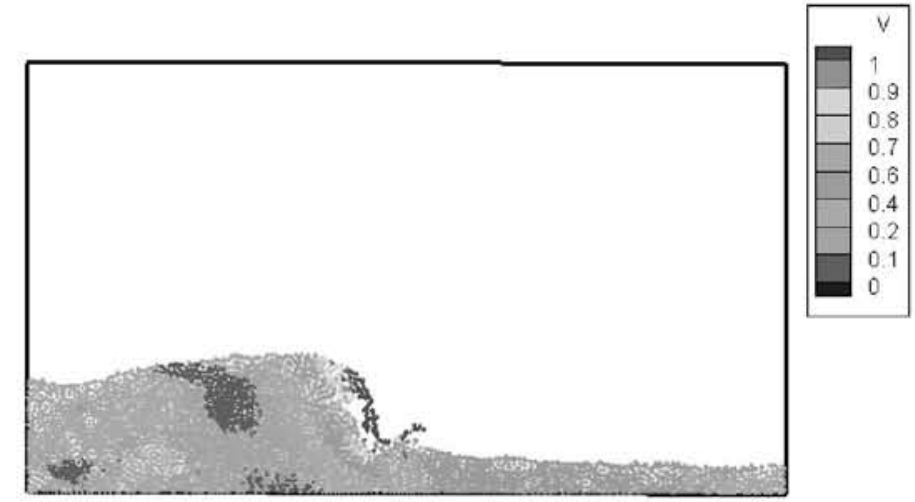

Figure 13 SPH velocity field. $t / T 0=8.85$ (see Fig. 10 for details)

in the damping characteristics of the three liquids is remarkable in this case (Figs. 14 and 15).

\subsubsection{Amplitude $=150 \mathrm{~mm}$}

In this case, the empty tank tests lasted only for 11 periods before getting to the limit angle. The damping characteristics were affected by the breaking waves in this case as well but to a lesser extent in comparison with amplitudes $50 \mathrm{~mm}$ and $100 \mathrm{~mm}$. The reduction ratios range from $46.7 \%$ for the water to $58.7 \%$ for the glycerin (Table 4 , analysis performed from 0 to $24.3 \mathrm{~s}$, end time in the empty tank experiment). Comparing SPH and water, the error is small (1\%) in terms of the reduction factor (Fig. 16, Table 4).

\subsection{Off-Resonance cases}

\subsubsection{General}

From the engineering point of view, off-resonance cases are not so important as the resonance ones. In off-resonance cases, the response amplitude of the structure is limited and if the excitation period is close to the resonance one, nice beating phenomena take place, like those represented in Fig. 6. In the present study, $0.9 \omega_{0}$ and $1.1 \omega_{0}$ excitation frequencies have been considered, with the same amplitudes as the resonance ones. A summary of the cases was documented in Table 1. We will focus on two of those cases, one below the natural frequency and one above.

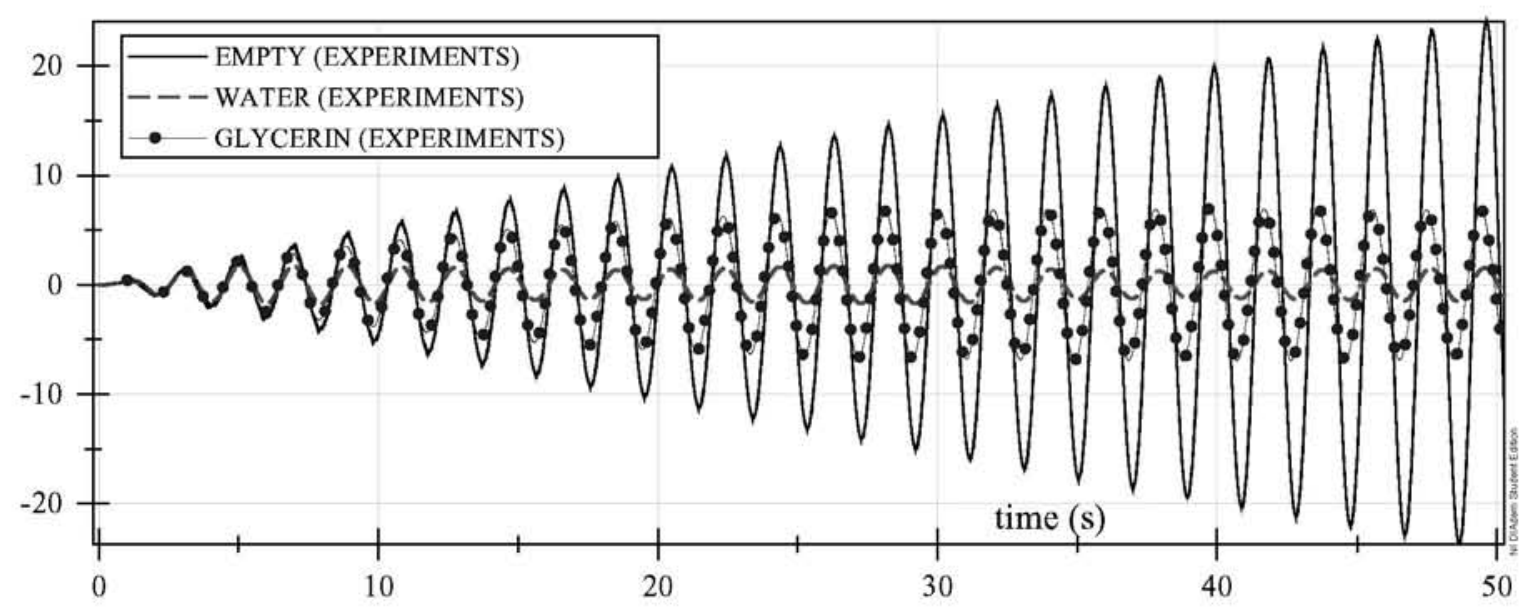

Figure 14 Roll angle, $A=50 \mathrm{~mm}, \omega=\omega_{0}$

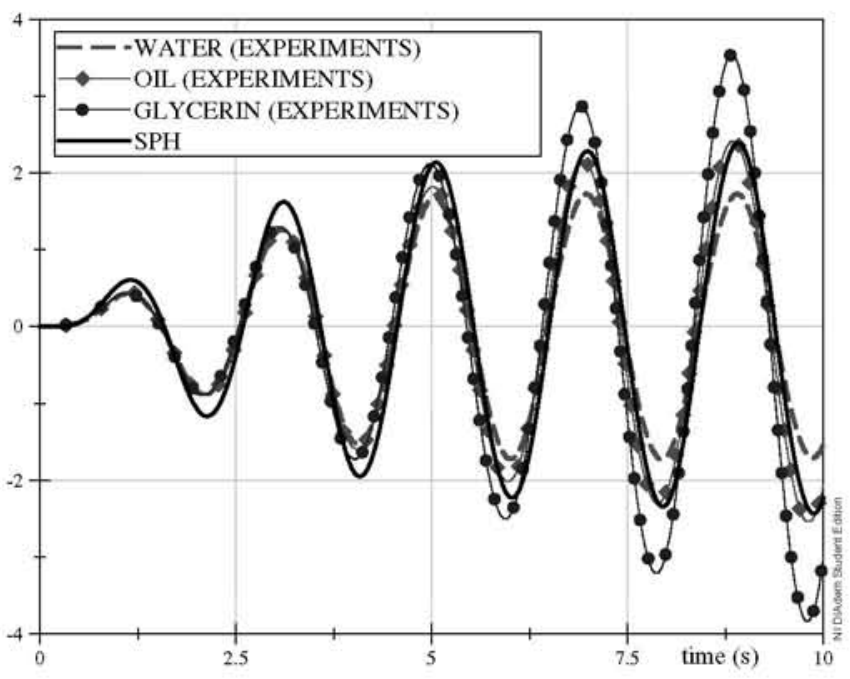

Figure 15 Roll angle (zoom). Roll angle, $A=50 \mathrm{~mm}, \omega=\omega_{0}$

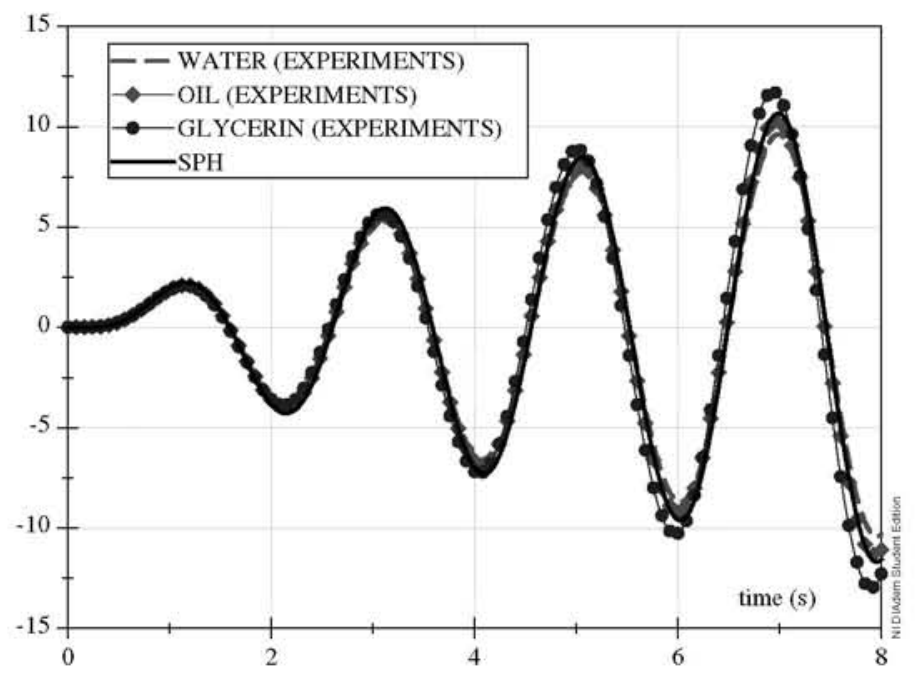

Figure 16 Roll angle, $A=150 \mathrm{~mm}, \omega=\omega_{0}$ 


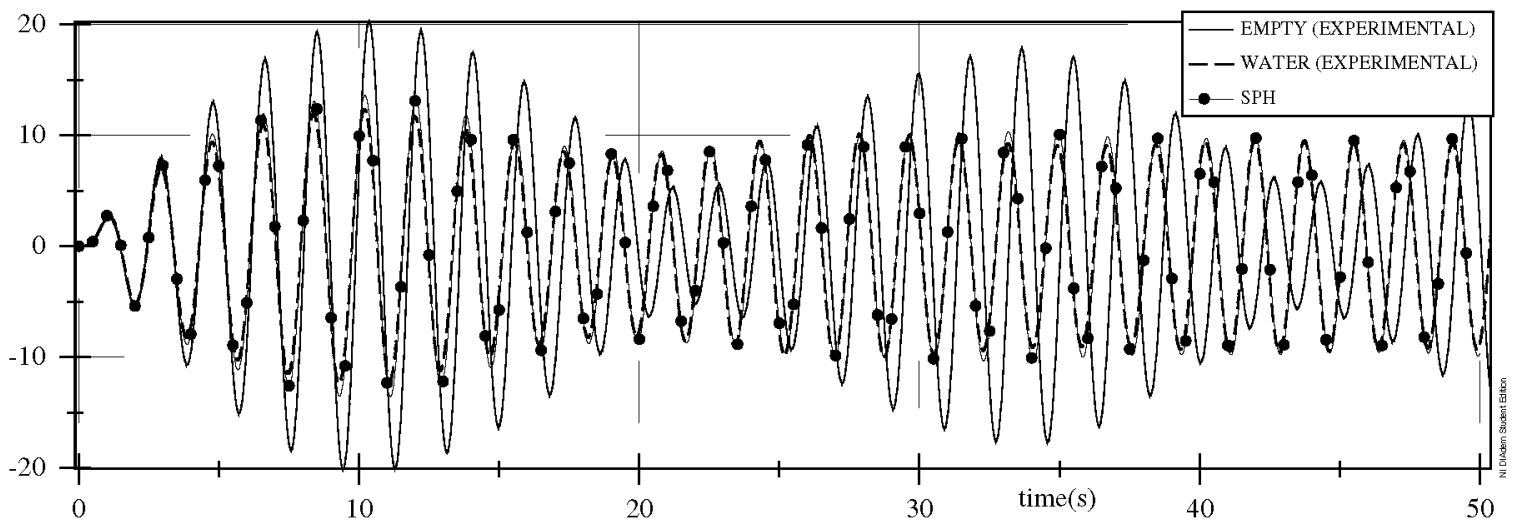

Figure 17 Roll angle, $A=200 \mathrm{~mm}, \omega=1.1 \omega_{0}$

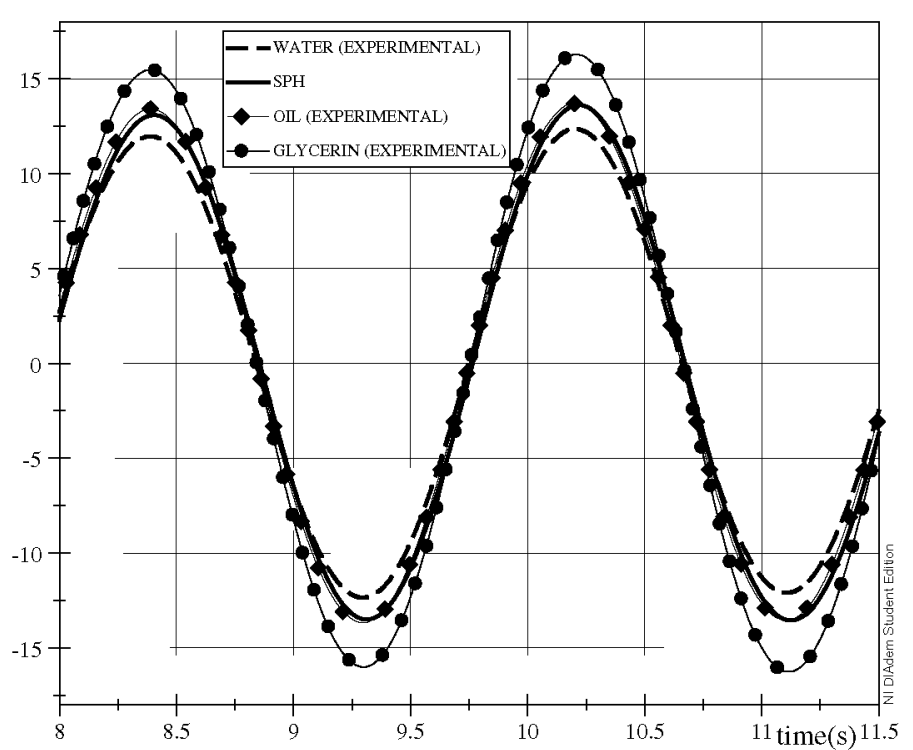

Figure 18 Roll angle (zoom), $A=200 \mathrm{~mm}, \omega=1.1 \omega_{0}$

Analysing those cases, it is possible to see that in off-resonance conditions, the beating phenomena that appears is modulated by the liquid damping and taken to a constant amplitude oscillation (Figs. 17 and 19). As can be seen in those figures, SPH is able to capture these phenomena.
In resonance conditions it was observed that the damping due to water was larger than the damping due to oil. It was also observed that the damping due to oil was larger than that with glycerin. In off-resonance conditions, this trend is not maintained. In some cases, water will provide greater dampings (Fig. 18) and in other conditions, this will be achieved by oil for instance (Fig. 20). This needs further research but may be related to some shift in the response due to viscosity. SPH is able to detect that shift in trend, as can be observed in Figs. 18 and 20 .

\section{Conclusions and future work}

The roll motion response of a single degree of freedom (SDOF) structural system to which a rigid rectangular partially filled liquid tank has been attached has been considered. The SDOF system has been described analytically and this description tested experimentally by applying to the system periodic excitations, finding that the response is accurately reproduced by the model which enables this model to describe analytically the rigid system. Only some small deviations between the model and the experiments at small angles have been detected. A better modelling of the friction damping for the rigid system would be necessary in the case of interest in the region of small rolling

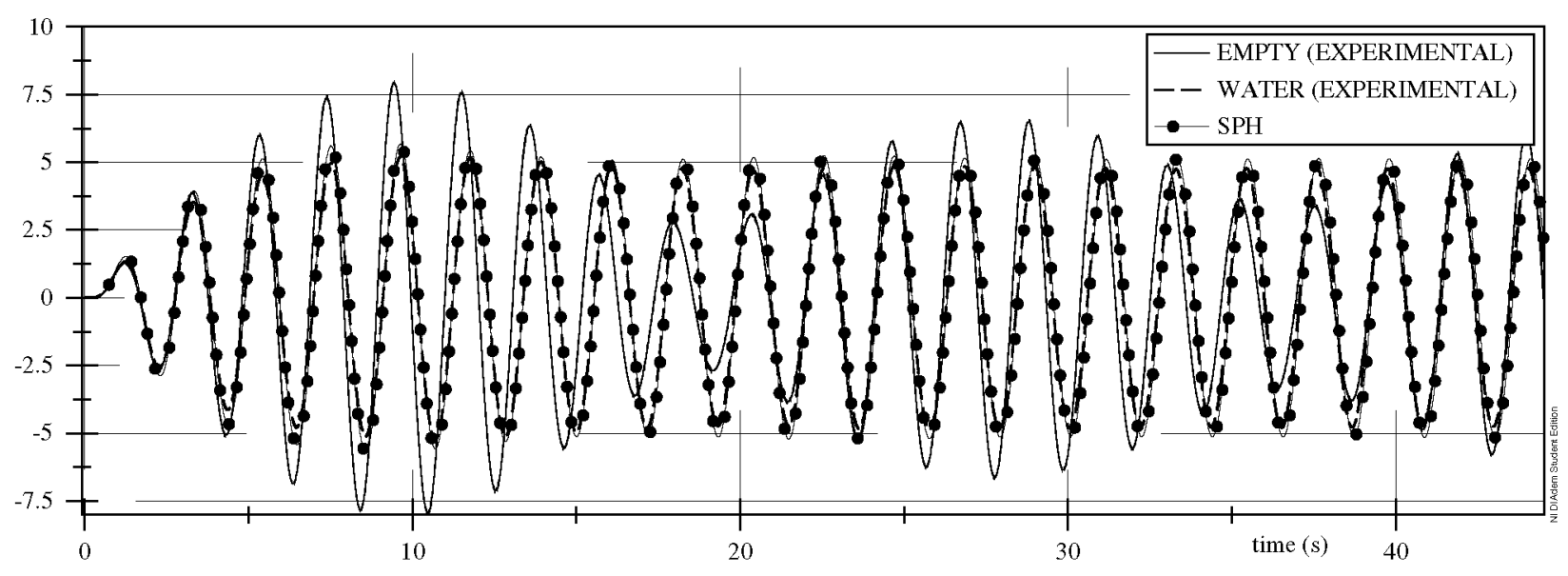

Figure 19 Roll angle, $A=100 \mathrm{~mm}, \omega=0.9 \omega_{0}$ 


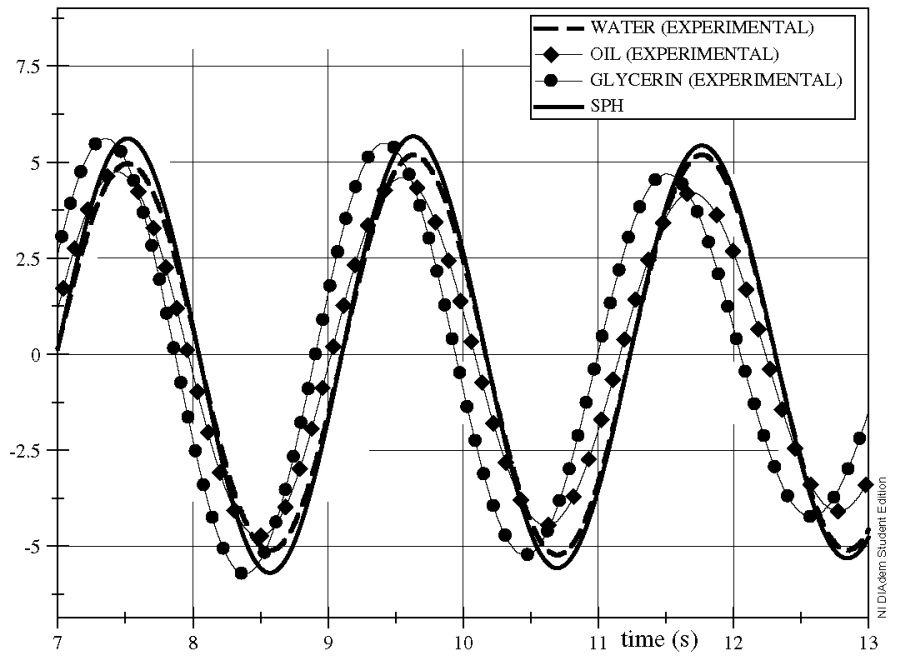

Figure 20 Roll angle (zoom), $A=100 \mathrm{~mm}, \omega=0.9 \omega_{0}$

amplitudes. Another option would be to modify the system in order to reduce the damping.

The capabilities of SPH to treat this coupling problem have been assessed. From the comparisons with the experiments, it seems SPH is able to capture part of the dissipation effects due to wave breaking which is reflected in reasonably accurate damping reduction ratios. Nevertheless, it is not at this stage possible to separate those effects from the shear ones in the boundary layers and in the bulk of the fluid, for which the SPH approach is not yet completely consistent with the Reynolds numbers of the experiments. Further work has to be done in regard to this. SPH is also able to simulate the off-resonance conditions, capturing the trend shifts in condtions below and above the natural frequencies.

It would be very interesting to compare these results with those obtained with other methods. To achieve this, application to angular motions of the techniques used for linear TLDs will be assessed as well as the possibility of treating this problem with a commercial CFD.

The work presented in this paper has dealt with a very controlled situation, with a simple dynamical system that can be analytically modelled with a level of accuracy such that the underlying analytical model for the dynamic system can be considered practically "exact" in engineering terms. According to this, the majority of discrepancies between experiments and simulations with the partially filled tank could be attributed to the SPH simulation (apart from the case of small amplitude oscillations where the inaccurate modelling of damping could have been a non negligible source of differences). Taking into account the fact that the agreement between experiments and simulation was, in general, good, we could conclude that the SPH approach, although still needing improvements on some aspects, could serve as a practical tool for the assessment of tanks' performances. The next steps that could be followed along this path are:

- Introduction and consequent experimentation/simulation of cases with the tank equipped with baffles as dissipation means.

- Implementation of a mathematical model for ship motions. In such case SPH could be used as a means to study, e.g., the effect of water on deck, in addition to the study of anti-rolling devices.
Moreover, effects like parametric excitation induced by vertical ship motions on the fluid could also be studied. Another interesting topic deserving attention are the fluid impact effects due to the fluid sloshing in a tank coupled with/forced by ship motions.

\section{Notation}

$A=$ Amplitude of the moving weight shift

$B_{\phi}=$ Linear damping term

$g=$ Gravitational acceleration

$I_{0}=$ Polar moment of inertia of the rigid system with respect to the rotation axis

$K_{d f}=$ Dry friction coefficient

$m=$ Mass of the sliding mass

$M_{R}=$ Total mass of the rigid system

$Q_{\text {damp }}(t)=$ Assumed form of roll damping moment

$Q_{\text {fluid }}(t)=$ Moment due to fluid action

$S_{G}=$ Static moment of the rigid system with respect to the rotation axis

$T=$ Period of the sliding mass

$T 0=$ Natural period of the rigid system

$\eta_{G}=($ Signed) distance of the centre of gravity of the Rigid system with respect to the rotation axis (tank-fixed reference system)

$\phi=$ Roll angle

$\xi_{m}(t)=$ Instantaneous (imposed) position of the excitation weight along the linear guide (tank-fixed reference system)

$\dot{\xi}_{m}(t)=$ First time derivative of $\xi_{m}(t)$

$\dddot{\xi}_{m}(t)=$ Second time derivative of $\xi_{m}(t)$

$\omega_{0}=$ Natural frequency of the rigid system

\section{References}

Armenio, V., Francescutto, A., La Rocca, M. (1996). On the roll motion of a ship with partially filled unbaffled and baffled tanks - Part 1: Mathematical model and experimental setup. Intl. J. Offshore and Polar Engng. 6(4), 278-282.

Armenio, V., Francescutto, A., La Rocca, M. (1996b). On the roll motion of a ship with partially filled unbaffled and baffled tanks - Part 2: Numerical and experimental analysis. Intl. J. Offshore and Polar Engng. 6(4), 283-290.

Attari, N.K.A., Rofooei, F.R. (2008). On lateral response of structures containing a cylindrical liquid tank under the effect of fluid/structure resonances. J. Sound and Vibration 318(4-5), 1154-1179.

Banerji, P., Murudi, M., Shah, A.H., Popplewell, N. (2000). Tuned liquid dampers for controlling earthquake response of structures. Earthquake Engng. \& Structural Dynamics 29(5), 587-602.

Bass, D.W. (1998). Roll stabilization for small fishing vessels using paravanes and anti-roll tanks. Marine Technology 35(2), 74-84. 
Bulian, G., Francescutto, A. (2004). A simplified modular approach for the prediction of the roll motion due to the combined action of wind and waves. J. Engng. for the Maritime Environment, Proc. of the Institution of Mechanical Engrs. 218, 189-212, Part M.

Colagrossi, A., Delorme, L., Colicchio, G., Souto-Iglesias, A., Cercós-Pita, J.L. (2008). Reynolds number and shallow depth sloshing. $3^{\circ}$ ERCOFTAC SPHERIC Workshop on SPH Applications.

Colagrossi, A., Landrini, M. (2003). Numerical simulation of interfacial flows by smoothed particle hydrodynamics. J. Comput. Phys. 191, 448-475.

Cummins, S.J., Rudman, M. (1999). An SPH projection method. J. Comput. Phys. 152(2), 584-607.

Delorme, L., Bulian, G., Mc Cue, L., Souto-Iglesias, A. (2006). Coupling between sloshing and ship roll motion: Comparison between first order potential theory and SPH. Proc. 26th Symposium on Naval Hydrodynamics. Italian Ship Model Basin (INSEAN), U.S. Office of Naval Research (ONR), 17-22, Rome, Italy.

Delorme, L., Colagrossi, A., Souto-Iglesias, A., ZamoraRodriguez, R., Botia-Vera, E. (2009). A set of canonical problems in sloshing. Part I: Pressure field in forced roll. Comparison between experimental results and SPH. Ocean Engng., 36(2), 168-178.

Dilts, G. (1999). Moving least squares particle hydrodynamics: consistency and stability. Intl. J. Numerical Methods in Engng. 44(8), 1115-1155.

Francescutto, A., Contento, G. (1999). An investigation of the applicability of simplified mathematical models to the rollsloshing problem. Intl. J. Offshore and Polar Engng. 9(2), 97-104.

Frandsen, J.B. (2005). Numerical predictions of tuned liquid tank structural systems. J. Fluids and Structures 20(33), 309-329.

Graham, E.W., Rodriguez, A.M. (1952). The characteristics of fuel motion which affects airplane dynamics. J. Applied Mechanics 19, 381-388.

Ikeda, T., Nakagawa, N. (1997). Non-linear vibrations of a structure caused by water sloshing in a rectangular tank. J. Sound and Vibration 201(1), 23-41.

Ikeda, T. (2003). Nonlinear parametric vibrations of an elastic structure with a rectangular liquid tank. Nonlinear Dynamics $33,43-70$.

Kareem, A., Kijewski, T., Tamura, Y. (1999). Mitigation of motions of tall buildings with special examples of recent applications. J. Wind and Structures 2(3), 201-251.
Koshizuka, S., Oka, Y. (1996). Moving-particle semi-implicit method for fragmentation of incompressible fluid. Nuclear Science and Engng. 123, 421-434.

Le Touzé, D., Oger, G., Alessandrini, B. (2008). Smoothed particle hydrodynamics simulation of fast ship flows. Proc. 27 th Symposium on Naval Hydrodynamics.

Lee, E.S., Moulinec, C., Xu, R., Violeau, D., Laurence, D., Stansby, P. (2008). Comparisons of weakly compressible and truly incompressible algorithms for the SPH mesh free particle method. J. Comput. Phys. 227(18) 8417-8436

Monaghan, J J. (1994). Simulating free surface flows with SPH. J. Comput. Phys. 110(2), 390-406.

Monaghan, J.J. (2005). Smoothed particle hydrodynamic simulations of shear flow. Monthly Notices of the Royal Astronomical Society 365, 199-213.

Pirner, M., Urushadze, S. (2007). Liquid damper for suppressing horizontal and vertical motions - parametric study. J. Wind Engng. and Industrial Aerodynamics 95, 1329-1349.

Reed, D., Yeh, H., Yu, J., Gardarsson, S. (1998). Tuned liquid dampers under large amplitude excitation. J. Wind Engng. and Industrial Aerodynamics 74-76(1), 923-930.

Rognebakke, O.F., Faltinsen, O.M. (2003). Coupling of sloshing and ship motions. J. Ship Research 47(3), 208-221.

Shao, S. (2005). SPH simulation of solitary wave interaction with a curtain-type breakwater. J. Hydr. Res. 43(4), 366-375.

Souto-Iglesias, A., Delorme, L., Rojas, P.L., Abril, S. (2006). Liquid moment amplitude assessment in sloshing type problems with SPH. Ocean Engng. 33, 11-12.

Sun, L.M., Fujino, Y. (1994). A semi-analytical model for tuned liquid damper (TLD) with wave breaking. J. Fluids and Structures 8(5), 471-488.

Tait, M.J., El Damatty, A.A., Isyumov, N. (2005). An investigation of tuned liquid dampers equipped with damping screens under 2D excitation. Earthquake Engng. \& Structural Dynamics 34(7), 719-735.

Tait, M.J., Deng, X. (2008). The performance of structuretuned liquid damper systems with different tank geometries. Structural Control and Health Monitoring.

van Daalen, E.F.G., Kleefsman, K.M.T., Gerrits, J., Luth, H.R., Veldman, A.E.P. (2001). Anti-roll tank simulations with a volume of fluid (VOF) based Navier-Stokes solver. Proc. 23rd Symposium on Naval Hydrodynamics.

van Den Bosch, J.J., Vugts, J.H. (1966). On roll damping by free-surface tanks. Trans RINA. 